\title{
Hot-mould foaming of modified hemicelluloses and hydroxypropyl methylcellulose
}

\author{
Kristina Karlsson ${ }^{1}$ (D) - Filip Nylander ${ }^{2} \cdot$ Malin Lundman $^{3} \cdot$ Marco Berta $^{4} \cdot$ Mats Stading $^{1,4} \cdot$ Gunnar Westman $^{2}$. \\ Mikael Rigdahl ${ }^{1}$
}

Received: 15 April 2019 / Accepted: 17 July 2019 / Published online: 1 August 2019

(C) The Author(s) 2019

\begin{abstract}
Plastics are a material group which have revolutionized the materials industry during the past century. However, the often fossil origin and littering of the material is problematic. Therefore, this study aims at exploring natural polymers, such as cellulose derivatives and hemicelluloses from different botanical origins, and demonstrate the possibility to use these polymers in a foaming application. The hemicelluloses were chemically treated in order to enhance their performance and foams with ratios as high as 4:1 of hemicellulose and the cellulose derivative, respectively, were successfully produced by a hot-mould foaming technique. The foams were found to be thermally stable up to about $280^{\circ} \mathrm{C}$. The chemical modifications were confirmed by Fourier transform infrared (FTIR) spectra and the foams were evaluated with regard to their liquid absorption capacity as well as their density. After $1 \mathrm{~min}$ the best foam absorbed $12.5 \mathrm{~g} / \mathrm{g}$ of liquid and after $30 \mathrm{~min}$ soak time and centrifugation the foams had absorption capacities between 2 and $5 \mathrm{~g} / \mathrm{g}$. All foams exhibited densities below $0.1 \mathrm{~g} / \mathrm{cm}^{3}$. In both the absorption test and density evaluation, the foams produced from mainly hemicellulose performed in a similar way as the reference foams based only on the cellulose derivative, which is considered an impressive result since cellulose is often reported to have superior properties to hemicelluloses.
\end{abstract}

Keywords Hemicelluloses $\cdot$ Xylan $\cdot$ Arabinoxylan $\cdot$ Hydroxypropyl methylcellulose $($ HPMC) $\cdot$ Foaming $\cdot$ Liquid absorption

\section{Introduction}

Plastics constitute a relatively new group of materials which has become one of the main engineering materials of our time, even replacing other materials such as wood, metals and glass in many applications. During the past century, the production and the use of plastic materials have increased rapidly [1]. Plastics exhibit relatively good mechanical properties in

Kristina Karlsson and Filip Nylander contributed equally to this work.

Kristina Karlsson

kristina.karlsson@chalmers.se

1 Department of Industrial and Materials Science, Chalmers University of Technology, SE-412 96 Gothenburg, Sweden

2 Department of Chemistry and Chemical Engineering, Chalmers University of Technology, SE-412 96 Gothenburg, Sweden

3 Essity Hygiene and Health AB, SE-405 03 Gothenburg, Sweden

4 Research Institutes of Sweden (RISE), Bioscience and Materials, PO Box 5401, SE-402 29 Gothenburg, Sweden relation to their low weight, as well as being very flexible when it comes to shaping and colouring possibilities. The wide selection of available polymers has made it possible to tailor the properties of plastics to fit almost any application, from inexpensive single-time applications to durable composite materials for the aero and automotive industry.

More recently though, the extensive use of plastic materials has been questioned. Numerous reports on large amounts of plastic waste floating in the oceans have been brought to attention [2,3]. Furthermore, leakage of small fragments of plastics into the soil is another growing concern. Plastic fragments have been found to potentially accumulate in earth worms, which might lead to further accumulation in other mammals, including humans, [4]. It is clear that plastics offer a great potential and value for the society, but the production, use and disposal of plastics have to be improved.

Foamed plastic is a special group of plastic products. By foaming the material, its weight can be substantially reduced. At the same time, the insulation, cushioning or absorption properties of the material can be improved. Expanded polystyrene (EPS) and polyurethane (PU) are examples of two 
common materials for producing plastic foams. The main disadvantages with these types of plastics are their often fossil origin as well as their slow degradation in nature [5], when not being properly disposed of. One way to overcome at least part of these problems can be to use polymers from nature instead of fossil-based ones. Many successful attempts of producing foamed materials from a renewable resource have been made using starch as the raw material. Starch foams have been produced with good results using a hot-mould technique [6-8], as well as by extrusion $[9,10]$.

Despite the promising properties of starch in this context, there is always a concern when working with materials which could potentially be utilized as a food resource. One idea could be to use a resource which is not edible by humans and which is not being utilized to its full potential as of today. Plants consist mainly of three primary constituents in varying proportions; cellulose, lignin and hemicellulose. Cellulose is a very important polymer and has several areas of application, for example in the form of paper products and also being the base material for production of different cellulose derivatives. Hydroxypropyl methylcellulose (HPMC) is a water soluble cellulose derivative, used widely in the pharmaceutical [11] and cosmetic industry as well as a food additive [12]. In addition, methyl cellulose (MC) have been investigated for use in packaging materials $[13,14]$. It is also known to give foams by using a hot-mould foaming technique [15], as well as by extrusion using water vapour as the blowing agent [16].

The hemicelluloses on the other hand are not often used commercially. One of the reasons for this is that there are several types of hemicelluloses, varying in structure and properties. Thus, it is not a very homogeneous polymer group and, furthermore, their molecular weight is rather low which put restrictions on their property profile. Moreover, the hemicelluloses are today often obtained in the form of diluted aqueous solutions which would require purification and concentration before they can be used as a material resource. However, it is of interest to take the necessary steps to asses to which extent these polymers can be transformed into useful compounds. This is also the topic of this paper. Today large amounts of hemicelluloses are burned for energy instead of being used as starting material for renewable plastics.

Here, the foaming ability of the hemicelluloses xylan (X) and two arabinoxylans (AX) with different botanical origin has been investigated by a hot-mould foaming technique.

Due to a poor foamability of native xylan during initial studies, the xylan hemicellulose was chemically modified with hydroxypropyl methyl before processing. The molecular structures of xylan and AX are displayed in Fig. 1, along with the introduced substitution groups which may be attached at different locations in the chain, possible locations are marked with an R. It is however not possible to assign the exact positions of the substitution groups in the materials produced here.
In previous work, it was shown that hydroxypropyl methylation of arabinoxylan [17] gave clouding, a thermoresponsive phase behaviour characteristic of HPMC. It then seemed likely that hydroxypropyl methylation of the hemicellulose backbone, a thermoresponsive hemicellulose with increased foamability and formation of stable hemicellulose ether phases in the foaming process, could be obtained. In order to improve the foamability all four samples were mixed with HPMC.

\section{Experimental}

\section{Materials}

Birch xylan, $\mathrm{X}_{\mathrm{bi}}$, was commercially obtained from SigmaAldrich (Schnelldorf, Germany). The arabinoxylan hemicelluloses originated either from barley husk, $\mathrm{AX}_{\mathrm{ba}}$, which was obtained from Lyckeby Culinar AB (Fjälkinge, Sweden) or from wheat bran, $\mathrm{AX}_{\mathrm{w}}$, which was supplied by Lantmännen (Stockholm, Sweden). The extraction of arabinoxylan from barley husk and wheat bran was performed by weak acid hydrolysis as previously reported [18-20]. The xylan and the arabinoxylan hemicelluloses were chemically modified with an etherification reaction, resulting in hydroxypropyl methylxylan $\left(\mathrm{HPMX}_{\mathrm{bi}}\right)$ and hydroxypropyl methylarabinoxylan HPMAX $_{\mathrm{ba}}$ and $\left.\operatorname{HPMAX}_{\mathrm{w}}\right)[17,21]$. The subscripts refer to the origin of the hemicelluloses which were xylan from birch and arabinoxylan from barley and wheat.

Hydroxypropyl methylcellulose (HPMC) from ShinEtsu Chemical Co (Tokyo, Japan) was used as received. HPMC is available in different grades, with molecular weights, and the specific grade used here was HPMC Metolose/60SH 4000, see Table 1 for details from the supplier. The choice of this grade was based on earlier foaming studies of HPMC [15].

\section{Methods}

\section{Modification of arabinoxylan (AX) and xylan (X)}

For the modification, $10 \mathrm{~g} \mathrm{AX}$ or $\mathrm{X}$ was pre-activated in $47 \mathrm{~mL} \mathrm{H}_{2} \mathrm{O}$ at $60{ }^{\circ} \mathrm{C}$ for $20 \mathrm{~min}$ followed by addition of $14.6 \mathrm{~g} \mathrm{NaOH}(50 \%)$ at $60{ }^{\circ} \mathrm{C}$ for $20 \mathrm{~min}$. Then propylene oxide $(5.3 \mathrm{~mL})$ and methyl iodide $(4.7 \mathrm{~mL})$ were added and the reaction formed a two-phase mixture that was stirred for 60-80 min under pressure in a closed reaction vessel. The two-phase mixture turned into a one-phase mixture and the temperature was raised to $90{ }^{\circ} \mathrm{C}$ for $60-90 \mathrm{~min}$, giving a viscous solution. The reaction was neutralized with $\mathrm{HCl}$ and precipitated using ethanol, isopropyl acetate and diethyl ether. The precipitate was dried and weighed. 
Fig. 1 The general molecular structure of a xylan backbone with possibly attached arabinose groups in the case of arabinoxylan. Also shown are the substitution groups (R) which were reacted onto the polymer chains

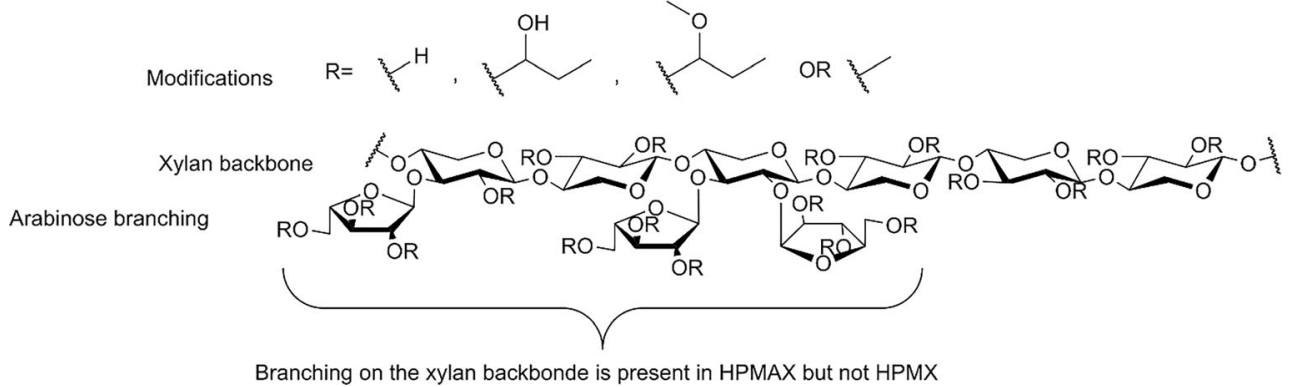

\section{Fourier transform infrared (FTIR) spectroscopy}

Fourier transform infrared spectra of the hemicelluloses were recorded using a PerkinElmer instrument with 8 scans per sample and a resolution of $1 \mathrm{~cm}^{-1}$. The samples (1\% by weight) were pressed into the form of $\mathrm{KBr}$ tablets. Three $\mathrm{KBr}$ tablets were made for each sample.

\section{Preparation and foaming of the materials}

The polymers in powder form were dispersed in water using a $90^{\circ} \mathrm{C}$ water bath and a magnetic stirrer. The solution was let to cool down and was then poured into circular aluminium foil moulds with a diameter of $40 \mathrm{~mm}$, placed on the bottom plate of a double hot-plated moulding machine (Franz Haas Waffelmaschinen, Austria). The plate temperature was set to $170{ }^{\circ} \mathrm{C}$ and the moulding time was $12 \mathrm{~min}$. No external pressure was applied, except of that exercised by the weight of the top plate on the sample when closing the mould. The concentration and proportion of the two polymers (hemicellulose and HPMC) were varied according to Table 2. During the moulding time, the water evaporated, and the vapour acted as a blowing agent facilitating the foaming.

\section{Shear viscosity at room temperature}

The viscosity of mixtures of different concentrations of hemicellulose and HPMC was determined at room temperature $\left(25^{\circ} \mathrm{C}\right)$. A strain-controlled rheometer (TA Instruments ARES-G2, USA) with a $40 \mathrm{~mm}$ diameter cone-plate geometry was used. The samples were tested in shear mode in the shear rate region 0.1 to $50 \mathrm{~s}^{-1}$ and at least two replicates were made for each sample.

\section{Thermal gravimetric analysis (TGA)}

Thermal gravimetric analysis of the foamed materials was performed using a MettlerToledo TGA/DSC 3+ Star System instrument. Here, $2 \mathrm{mg}$ foamed material was taken for measuring the mass loss due to de-volatilization and chemical degradation from 25 to $550{ }^{\circ} \mathrm{C}$ at a rate of $10{ }^{\circ} \mathrm{C} / \mathrm{min}$. The purge gas was nitrogen at a flow of $60 \mathrm{~mL} / \mathrm{min}$.

\section{Microscopy}

An optical microscope, SteREO Discovery. V20, (ZEISS, Germany) was used to study the structure of the foamed samples. A foam-sample was sliced using a surgical stainless-steel blade (Swann-Morton, UK) and a slice of material was studied.

\section{Density}

The apparent density of the foams was evaluated by measuring the weight and approximating the volume. The weight of a sample was recorded using a balance (Mettler Toledo AG285, USA). The volume was approximated by measuring the diameter and the height of a foam sample. The density was then calculated as the mass divided by the volume. The density measurements were made in duplicate and the experimental error was estimated to be around $10 \%$.

\section{Absorption capacity}

The absorption capacity of the foams was evaluated by both the free swell capacity and the fluid retention capacity according to the standard test methods NWSP 240.0.R2 (15) and NWSP 241.0.R2 (15) [22]. Small pieces of the foam weighing
Table 1 The viscosity, methoxy content and hydroxypropyl content for HPMC Metolose/ $60 \mathrm{SH} 4000$ as given by the supplier

\begin{tabular}{lllll}
\hline Sample & Abbreviation & Viscosity (cP) $)^{\mathrm{a}, \mathrm{b}}$ & $\begin{array}{l}\text { Methoxy } \\
\text { content (\%) }\end{array}$ & $\begin{array}{l}\text { Hydroxypropoxyl } \\
\text { content (\%) }\end{array}$ \\
\hline HPMC Metolose/60SH 4000 & HPMC60-4000 & 4000 & $28.0-30.0$ & $7.0-12.0$ \\
\hline
\end{tabular}

a 2 wt. $\%$ aqueous solution at $20^{\circ} \mathrm{C}$ according to the USP measuring method; Shin-Etsu Chemical co. http://www. metolose.jp/e/pharmaceutical/metolose.shtml

${ }^{\mathrm{b}}$ Note that $1 \mathrm{cP}$ is equal to $1 \mathrm{mPa} \cdot \mathrm{s}, \mathrm{cP}$ is the unit used by the manufacturer 
Table 2 The proportions of the two polymers and the concentration of the solutions in weight-\% (wt-\%) used for the foaming experiments

\begin{tabular}{|c|c|c|}
\hline Polymers & Proportion & Dry content (wt-\%) \\
\hline HPMC: HPMAX & $2: 1$ & 7 \\
\hline HPMC: $H_{P M A X}$ & $1: 1$ & 5 \\
\hline HPMC: $H_{P M A X}$ & $1: 2$ & 7 \\
\hline HPMC: $\operatorname{HPMAX}_{\mathrm{ba}}$ & $1: 4$ & 12 \\
\hline $\operatorname{HPMAX}_{\mathrm{ba}}$ & - & 30 \\
\hline HPMC: $\operatorname{HPMAX}_{\mathrm{w}}$ & $2: 1$ & 7 \\
\hline HPMC: $\operatorname{HPMAX}_{\mathrm{w}}$ & $1: 1$ & 5 \\
\hline HPMC: $\operatorname{HPMAX}_{\mathrm{w}}$ & $1: 2$ & 7 \\
\hline HPMC: $\operatorname{HPMAX}_{\mathrm{w}}$ & $1: 4$ & 12 \\
\hline HPMAX $_{\mathrm{w}}$ & - & 30 \\
\hline HPMC: $H_{P M X}$ & $2: 1$ & 7 \\
\hline HPMC: $\mathrm{HPMX}_{\mathrm{bi}}$ & $1: 1$ & 5 \\
\hline HPMC: $H_{P M X}$ & $1: 2$ & 7 \\
\hline HPMC: $H_{P M X}$ & $1: 4$ & 12 \\
\hline HPMC: $\mathrm{HPMX}_{\mathrm{bi}}$ & - & 30 \\
\hline HPMC:GGM & $2: 1$ & 7 \\
\hline HPMC:GGM & $1: 1$ & 5 \\
\hline
\end{tabular}

between 0.1 and $0.2 \mathrm{~g}$ were cut from a larger sample. The pieces were placed in bags which were sealed by heat. The bag was made of a poly(ethylene terephtalate) monofilament fibre material, SEFAR PETEX 07-59/33. The samples were thereafter weighed again, together with the bags, before being dipped into a test liquid which was a $0.9 \% \mathrm{NaCl}$ aqueous solution. After being immersed into the liquid, the samples were left hanging to let any excess fluid drip off before the sample weight was measured again. Unlike in the standard method, the step of dripping for 10 min was changed to $2 \mathrm{~min}$. The free swell capacity was measured after 1,5 and $30 \mathrm{~min}$. The test was repeated four times for each foam sample and average values are reported. The experimental error was estimated to be around $10 \%$.

\section{Results and discussion}

\section{Modifications}

Successful modification of xylan and arabinoxylan with hydroxypropyl and methyl groups was confirmed using FTIR, Fig. 2. The fundamental vibrations of hydroxypropyl groups were found as $\mathrm{C}-\mathrm{H}$ stretching signals at $2973 \mathrm{~cm}^{-1}, 2932 \mathrm{~cm}^{-1}$ and $2880 \mathrm{~cm}^{-1}$ as well as the C$\mathrm{H}$ bending at $1380 \mathrm{~cm}^{-1}$. The $\mathrm{C}-\mathrm{H}$ stretch signal at $2845 \mathrm{~cm}^{-1}$ and the $\mathrm{C}-\mathrm{H}$ bend signal at $1461 \mathrm{~cm}^{-1}$ are characteristic for the methyl groups.

The characteristic differences in signals between the xylan and the arabinoxylan were observed for the HPMAX and the

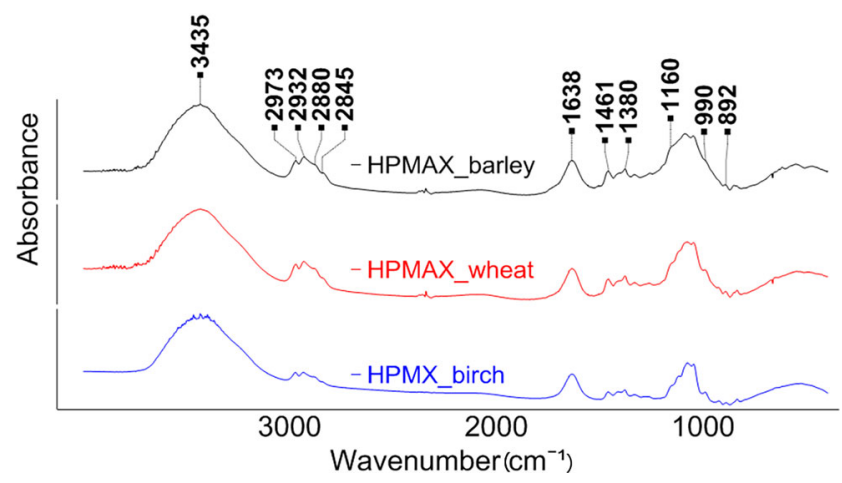

Fig. 2 FTIR spectra of modified hemicelluloses; HPMAX ${ }_{\mathrm{ba}}$ (top), HPMAX $_{\mathrm{w}}$ (middle) and HPMX the hydroxypropyl $\left(2973,2932,2880,1380 \mathrm{~cm}^{-\mathbf{1}}\right)$, methyl (2845, $\left.1461 \mathrm{~cm}^{-1}\right)$ and xylan $\left(3400,1638,1160,990,892 \mathrm{~cm}^{-1}\right)$ structures in the spectra are found

HPMX spectra in the fingerprint region (below $1250 \mathrm{~cm}^{-1}$ ). The weak signal at $892 \mathrm{~cm}^{-1}$ is specific for the branched arabinoxylan and do not show up in the xylan. All spectra contain the $\mathrm{O}-\mathrm{H}$ vibrations at $3400 \mathrm{~cm}^{-1}$ and the signals from water of hydration at $1638 \mathrm{~cm}^{-1}$ that are characteristic for both arabinoxylans and xylans [23]. Variation in the distribution pattern of arabinose side chains between barley and wheat arabinoxylan is a feature known to influence properties [24]. Side chain signals are in the convoluted part of the fingerprint region (around $1000 \mathrm{~cm}^{-1}$ ) where the sum of signals from side chain and backbone structure gave unique features for each sample. For periodic side chain patterns the Fourier transform spectra were too rich in information and complicated to analyze only from signals. Since the distribution of side chains can influence foamability barley and wheat arabinoxylan were included for analysis of foam properties.

\section{Thermal stability}

The thermal stability of the foams was assessed by TGA. As shown in the case of the HPMC:HPMX $\mathrm{bi}$ 1:1 foam in Fig. 3, the mass loss curves were uniform for all the foamed

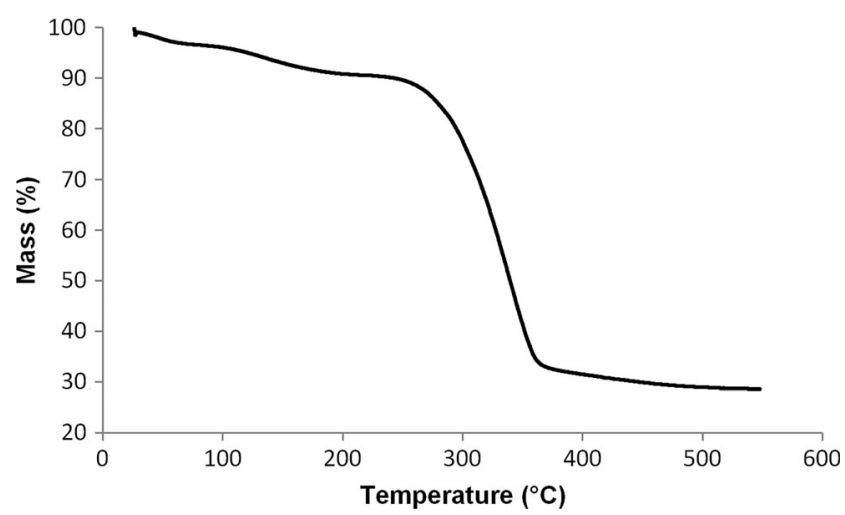

Fig. 3 TGA curve showing the thermal degradation of a foam of HPMC: HPMX $_{\mathrm{bi}} 1: 1$, with an onset temperature for thermal degradation in the range of $280-290{ }^{\circ} \mathrm{C}$ 
polymers. The onset temperature for thermal degradation of all foams was in the range of $280-290^{\circ} \mathrm{C}$. The main mass loss process for the foamed polymers continued up to $360^{\circ} \mathrm{C}$ and the remaining de-volatilization took place at a low rate. The onset temperature was about $100{ }^{\circ} \mathrm{C}$ above the plate temperature used for foaming, indicating thermal stability and a window for increasing the temperature during the foam manufacturing.

Table 3 shows the onset temperature $\left(\mathrm{T}_{\mathrm{o}}\right)$, the degradation temperature at maximum degradation rate $\left(\mathrm{T}_{\max }\right)$ and the residual mass values for all of the measured foams.

\section{Shear viscosity of the polymer solutions at room temperature}

The shear viscosity was measured as a function of the shear rate for ten of the hemicelluloses and hemicellulose-HPMC blends. The results, which are displayed in Fig. 4 show that most of the hemicellulose-HPMC blends exhibited a common polymeric, shear-thinning behaviour, meaning that the viscosity decreased with increasing shear rate. Most of the dissolved blends had viscosities starting between 10 and $30 \mathrm{~Pa} \mathrm{~s}$, decreasing to about 4-10 Pa s, at shear rates increasing from 0.1 to $50 \mathrm{~s}^{-1}$. Two of the blends exhibited slightly higher initial viscosities, 40-60 Pa s, at low shear rates, which is not surprising since these solutions had the highest concentration; HPMC:HPMX $\mathrm{bi}_{\mathrm{bi}}$ 1:4 and HPMC:HPMAX $\mathrm{w}_{\mathrm{w}}$ 1:4. However, the third blend with the same polymers concentration (HPMC:HPMAX ${ }_{\text {ba }}$ 1:4) exhibited a lower viscosity, being in the same range as the majority of the other dissolved blends. Furthermore, the sample based only on hemicellulose (HPMX $\left.\mathrm{bi}_{\mathrm{b}} 30 \mathrm{wt}-\%\right)$, did not behave as the blends. The viscosity was quite low, around $0.3-0.4 \mathrm{~Pa}$ s and more or less constant throughout the experiment, i.e. it behaved almost like a Newtonian fluid. A viscosity within a certain range, being low enough to allow bubble growth, but high enough to stabilize the foam structure during the water evaporation phase, is believed to be of importance for a successful, stable, foam formation.

Table 3 Data from TGA curves of foamed polymers. $T_{0}$ is onset temperature and $\mathrm{T}_{\max }$ is degradation temperature at maximum degradation rate

\begin{tabular}{|c|c|c|c|}
\hline Sample & $\mathrm{T}_{\mathrm{o}}\left({ }^{\circ} \mathrm{C}\right)$ & $\mathrm{T}_{\operatorname{Max}}\left({ }^{\circ} \mathrm{C}\right)$ & Residual mass (\%) \\
\hline HPMC:HPMX ${ }_{\mathrm{bi}} 1: 1$ & $280-290$ & 325 & 29 \\
\hline HPMC:HPMX ${ }_{\mathrm{bi}} 1: 4$ & $280-290$ & 325 & 37 \\
\hline HPMC:HPMAX ${ }_{\mathrm{ba}} 1: 1$ & $280-290$ & 320 & 28 \\
\hline HPMC:HPMAX ${ }_{\mathrm{ba}}$ 1:4 & $280-290$ & 320 & 37 \\
\hline HPMC:HPMAX ${ }_{w}$ 1:1 & $280-290$ & 325 & 27 \\
\hline HPMC:HPMAX ${ }_{\mathrm{w}}$ 1:4 & $280-290$ & 325 & 37 \\
\hline
\end{tabular}

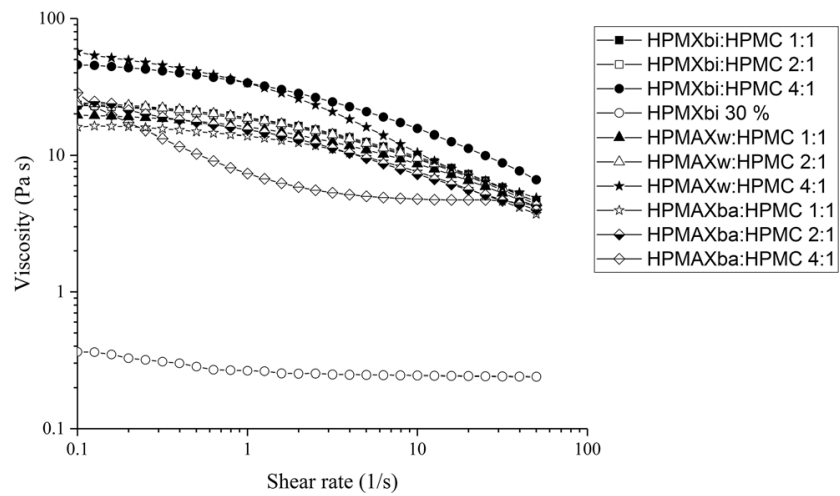

Fig. 4 The shear viscosity shown as a function of the shear rate for eleven aqueous solutions of hemicellulose and hemicellulose-HPMC blends. A majority of the blends had viscosities starting between 10 and $30 \mathrm{~Pa} \mathrm{~s}$, decreasing to about 4-10 $\mathrm{Pa} \mathrm{s}$, at shear rates increasing from 0.1 to $50 \mathrm{~s}-1$

\section{The foaming ability}

A previous initial study, where unmodified birch xylan was mixed with HPMC and foamed with the same hot-mould process, showed that the foaming ability of the HPMC decreased by an increasing addition of the xylan. At a 1:1 concentration only flat, brittle films and no foam structure was obtained. However using the modified hemicelluloses in the blends with HPMC, foamed structures could be produced in a rather straightforward manner and foamed structures of varying quality were formed. Figure 5 shows optical micrographs of foams containing 1 part of HPMC and 1, 2 or 4 parts of $\operatorname{HPMAX}_{w}$, as well as one foam containing only $\operatorname{HPMAX}_{\mathrm{w}}$ (initial concentration 30 weight-\%). At equal amounts of hemicellulose and HPMC, the foams at a first glance seemed to expand to an appreciable extent, but upon slicing the foams it was clear that the structure was hollow and mainly consisted of one big bubble, cf. Fig. 5. When the amount of hemicellulose was doubled, the structure had a somewhat more connected structure in the middle of the foams, but was still dominated by large voids. When increasing the ratio to 4 parts of HPMAX $_{\mathrm{w}}$ and 1 part of HPMC, the structure became significantly more even. The inside of the foam now exhibited a more even pore distribution, even though the pore-size distribution is probably broad. Some pores appeared to be about $2000 \mu \mathrm{m}$ in diameter. The foam that contained only HPMAX $_{\mathrm{w}}$ was hard, brittle and barely expanded at all. The structure did not fill the mould and the specimen appeared more like a few millimetre-thick film adhering to the bottom of the heated plate.

Figure 6 shows corresponding micrographs of foams containing 1 part of HPMC and 1, 2 or 4 parts of $\operatorname{HPMAX}_{\mathrm{ba}}$, as well as one foam containing only $\operatorname{HPMAX}_{\mathrm{ba}}$ (initial concentration 30 weight-\%). A similar behaviour as for the HPMAX $_{\mathrm{w}}$ and HPMC foam formed at the 1:1 ratio was observed. The foam with a 1:1 ratio was hollow and the centre region consisted mainly of one large void. With the 1:2 ratio, 
Fig. 5 Cross-sectional images of foamed HPMC:HPMAX samples containing different proportions of the two polymers. The proportions were one part of HPMC and either 1, 2 or 4 parts of HPMAX $_{\mathrm{w}}$. One foam contained only $\operatorname{HPMAX}_{\mathrm{w}}$
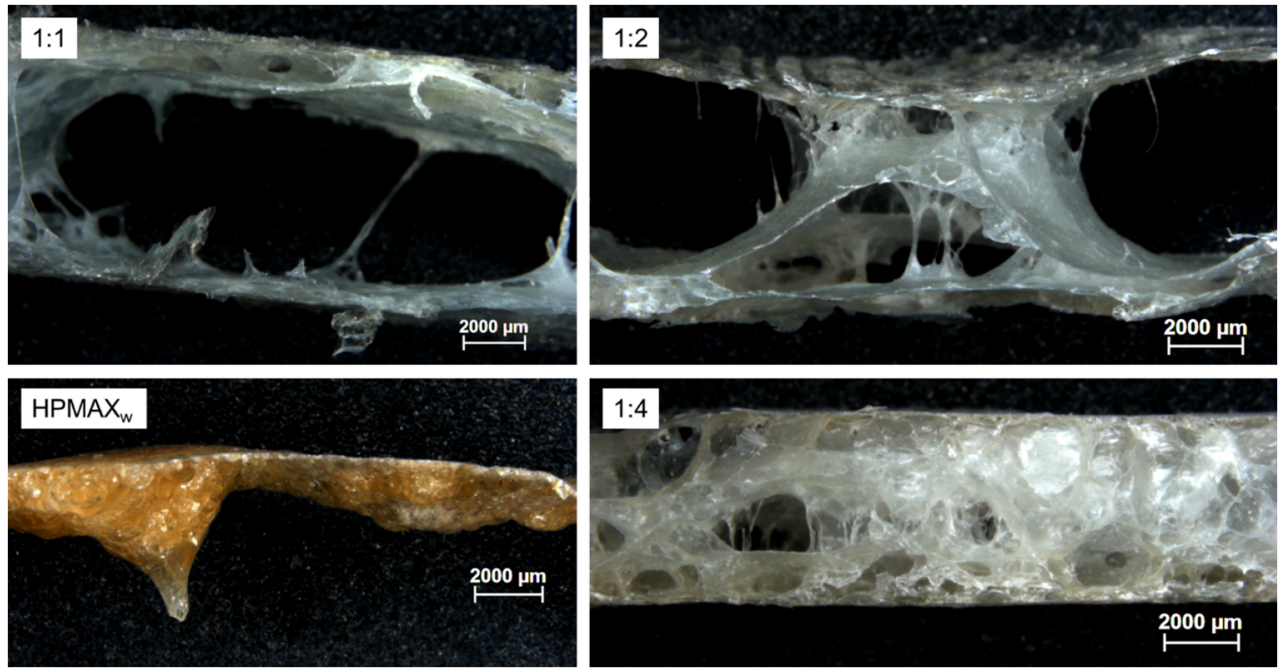

the structure was more connected, see Fig. 6. However, a darker colour appeared, as can be seen at the top and bottom of the sample. In the foam with the 1:4 ratio of HPMC and hemicellulose content, a clear darkening of the sample took place. The darkening may indicate that some degradation of the hemicelluloses is initiated. The foam containing only HPMAX $_{\mathrm{ba}}$ was hard, brittle and with a poor expansion compared to the foams with some HPMC addition. The colour of this foam was even darker than for the mixed ones.

Figure 7 shows micrographs of foams containing 1 part of HPMC and 1, 2 or 4 parts of HPMX $\mathrm{bi}_{\mathrm{bi}}$. Foams containing this type of modified hemicellulose exhibited a more uniform internal porosity, already at low mixing ratios (1:1 and 1:2 of HPMC: HPMX $\mathrm{bi}_{\mathrm{bi}}$, compared to the other types. At the 1:4 ratio, the foam was of a slightly darker colour and it was somewhat brittle. The modified HPMAX ba $_{\text {had initially a }}$ somewhat more brownish appearance than the other hemicelluloses and the dark colour is thus not unexpected. However, also in this case, an onset of thermal degradation cannot be excluded. It was not possible to obtain any image of a foam containing only $\mathrm{HPMX}_{\mathrm{bi}}$, since the foaming ability was very poor, i. e only thin and fragile films were obtained from the experiments.

Figure 8 shows micrographs of the best foams from each hemicelluloses-HPMC blend. For HPMC:HPMAX $\mathrm{ba}_{\mathrm{ba}}$ and HPMC:HPMX ${ }_{\mathrm{bi}}$, the blend ratio 1:2 produced the best foams. For the HPMC:HPMAX $\mathrm{w}_{\mathrm{w}}$ foam, a ratio of 1:4 appeared to exhibit a better foamability. Out of the three, the HPMC:HPMAX ${ }_{\mathrm{ba}}$ foams seemed to provide a somewhat less promising pore structure. This may indicate that a further optimization of this modified hemicelluloses and the blending with HPMC together with a tuning of the foaming conditions is required in order to improve its foamability.

\section{Density}

The apparent densities of eight of the produced foamed samples were evaluated by weight measurements and volume approximations as described earlier. All foams from a combination of either $\mathrm{HPMX}_{\mathrm{b}}, \mathrm{HPMAX}_{\mathrm{w}}$ or $\mathrm{HPMAX}_{\mathrm{ba}}$ with HPMC,

Fig. 6 Cross-sectional images of foamed HPMC:HPMAX samples containing different proportions of the two polymers. The proportions were one part of HPMC and either 1, 2 or 4 parts of HPMAX $_{\mathrm{ba}}$. One foam contained only HPMAX
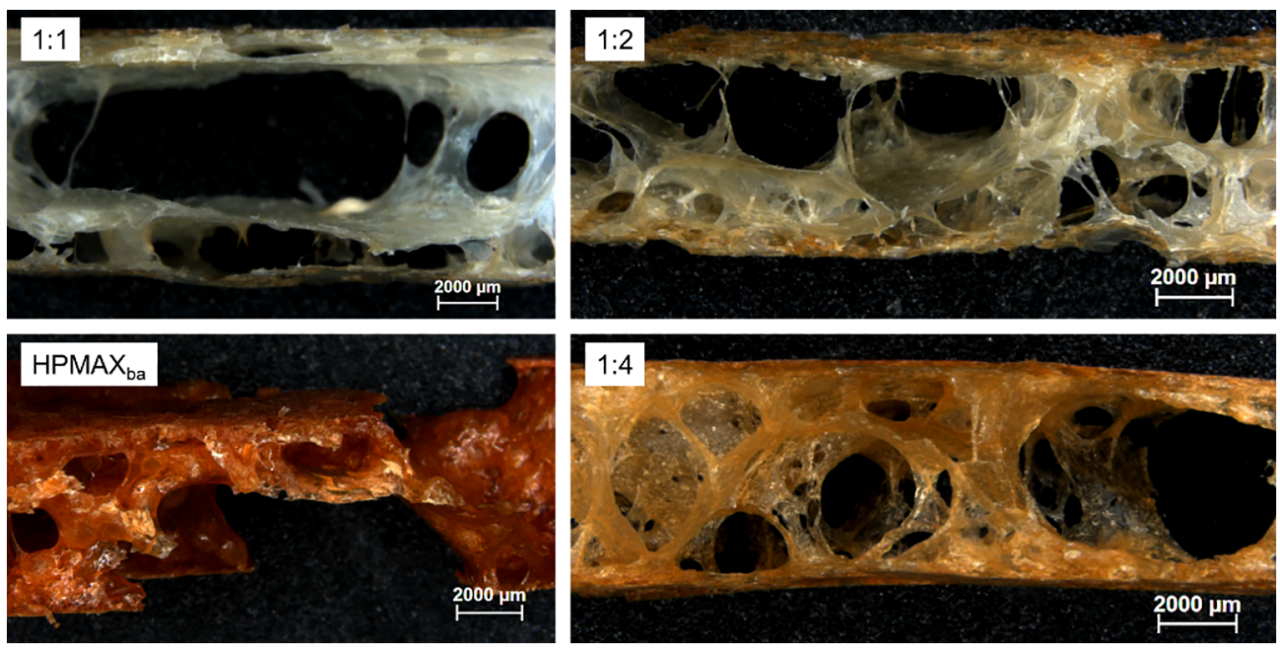
Fig. 7 Cross-sectional images of foamed HPMC:HPMX $\mathrm{bi}_{\mathrm{b}}$ samples containing different proportions of the two polymers. The proportions were one part of HPMC and either 1, 2 or 4 parts of HPMX $_{\mathrm{bi}}$
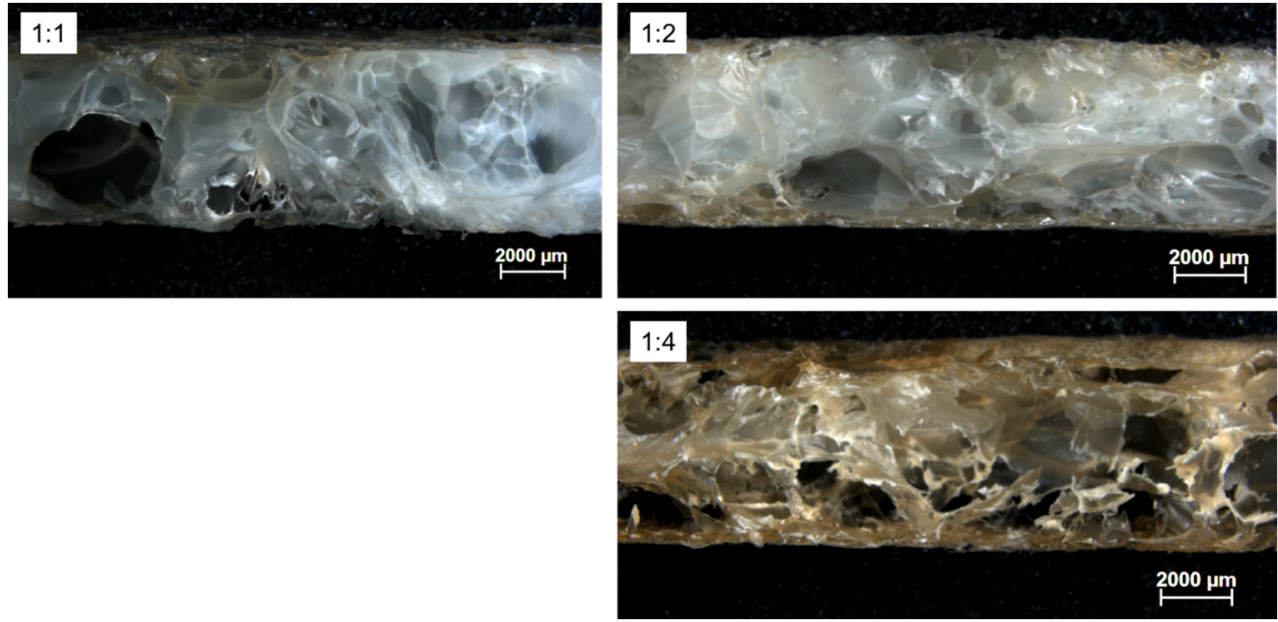

as well as the reference HPMC foam exhibited densities below $0.1 \mathrm{~g} / \mathrm{cm}^{3}$, see Fig. 9. The apparent densities were quite similar for all the foams, irrespective of the type of hemicelluloses used, but there was a slight tendency toward a higher density when the amount of hemicellulose increased. This may not indicate a general pattern, since the density of the HPMC foam actually was somewhat higher than those of the blends.
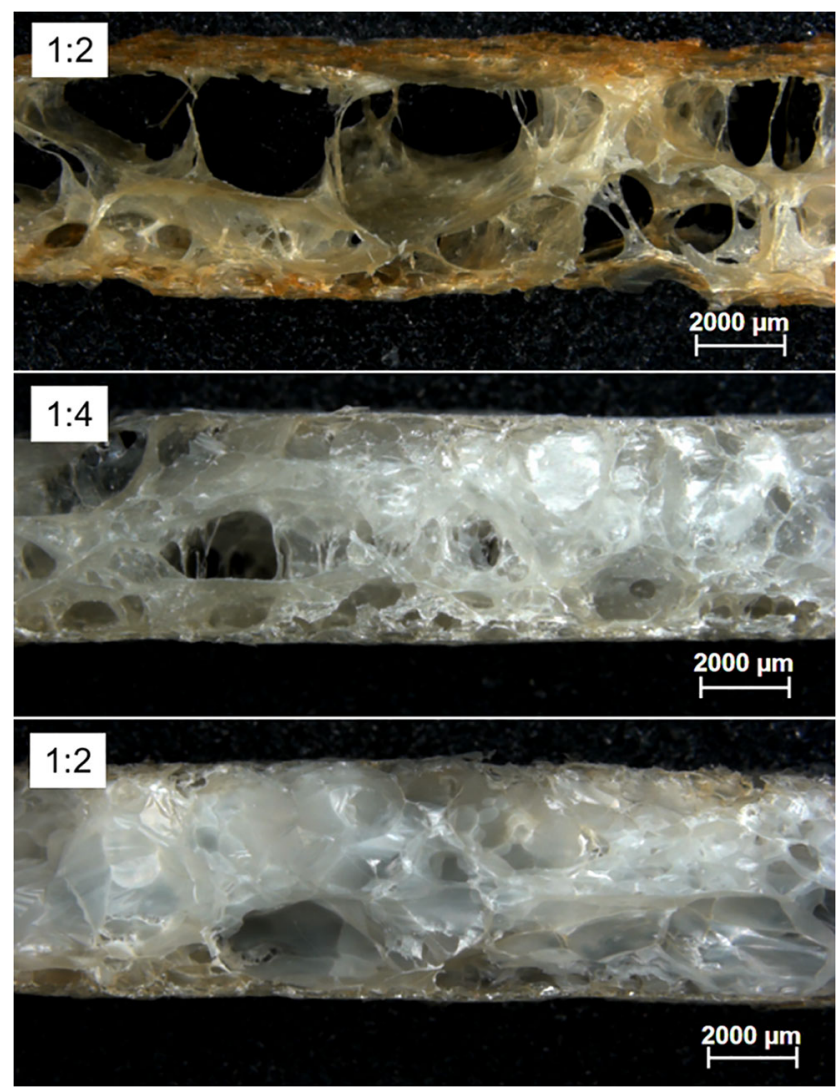

Fig. 8 Micrographs illustrating the best foams produced from each hemicellulose-HPMC blend. From the top to bottom: HPMC:HPMAX ${ }_{\text {ba }}$ 1:2, HPMC:HPMAX $1: 4$ and HPMC:HPMX $1: 2$
The apparent densities are in general quite low, which is positive in a sense. But, as evident from the micrographs above, the pore structures of the foams differ significantly and in some cases it may be argued that a pore structure is actually not at hand. To put the density values in perspective, expanded polystyrene foams usually have very low densities in the range of $0.015-0.03 \mathrm{~g} / \mathrm{cm}^{3}$ [25], whereas reported values for polyurethane foams are in the range of $0.1-0.7 \mathrm{~g} /$ $\mathrm{cm}^{3}$, depending on grade [26].

\section{Absorption capacity}

The absorption capacity of some of the produced foams is shown in Fig. 10. For the absorption test, the polymer blends that exhibited greater expansion during the foaming experiments were selected. The foam based only on HPMC was used as a reference. As seen in Fig. 10, all the tested foams exhibited a similar absorption pattern. The foams based on HPMC:HPMAX ${ }_{\text {ba }}$ 2:1, HPMC:HPMAX $1: 2$ and HPMC:HPMAX ${ }_{\mathrm{w}}$ 1:4 displayed the highest absorption after $1 \mathrm{~min}$ immersion; longer immersion times resulted in a decreased absorption capacity. Here, the HPMC:HPMAX ${ }_{\text {ba }} 2: 1$ foam exhibited the greatest absorption capacity with about $12.5 \mathrm{~g} / \mathrm{g}$ after a soak time of $1 \mathrm{~min}$. The reason for the decrease in water retention at longer times might be that the foamed structure collapsed, at least partly, quite rapidly when in contact with the fluid and thus the remaining water retention capacity would be attributed to a significant extent to the water holding capability of the polymers and not only to the porous structure. For the HPMC reference, the initial absorption after $1 \mathrm{~min}$ was greater than when measured after $5 \mathrm{~min}$, however, at $30 \mathrm{~min}$, the absorption was greater than after $1 \mathrm{~min}$. A similar trend could also be seen for some of the other samples. This behaviour might be due to a minor loss of material leaking into the aqueous phase in connection with the collapse of the foam structure. The remaining material possibly 
Fig. 9 The apparent density of eight of the produced foams. All the foams with a combination of hemicellulose and HPMC, as well as the reference HPMC sample, had densities below $0.1 \mathrm{~g} / \mathrm{cm}^{3}$

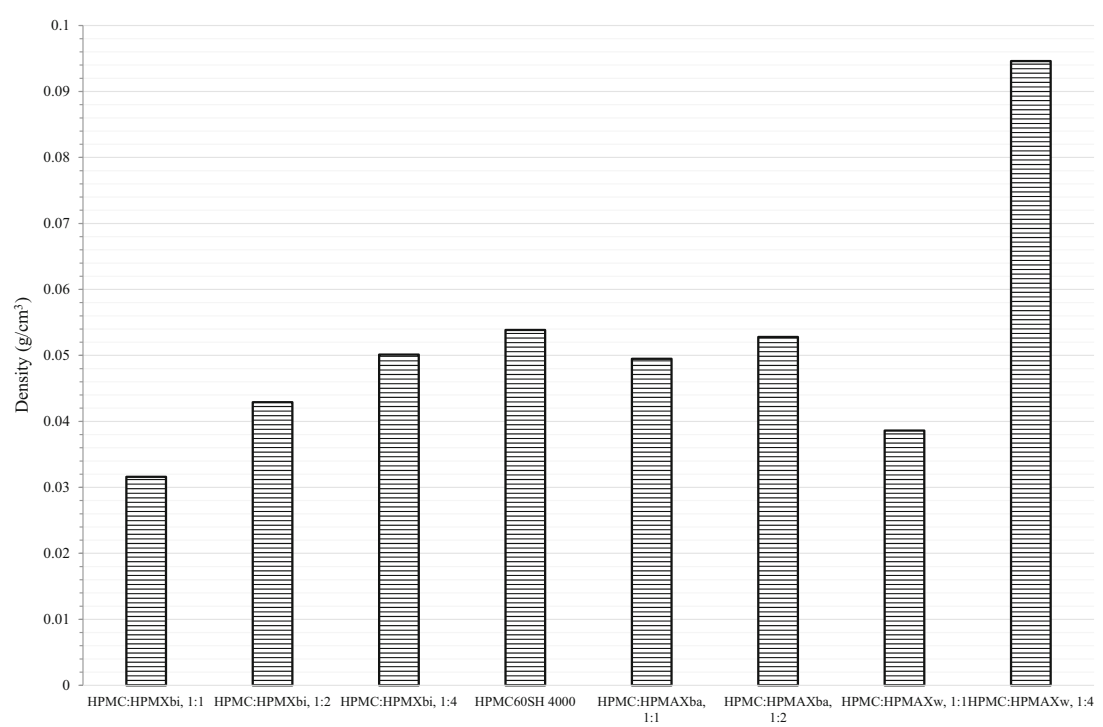

continues to absorb more liquid and eventually hold a greater amount than at the beginning of the test.

After the centrifugation, all foams have lost liquid and exhibited retentive capacities between 2 and $5 \mathrm{~g} / \mathrm{g}$. The HPMC reference showed here the greatest retentive capacity after centrifugation, which perhaps is not surprising since it is expected to be quite stable when in contact with water at room temperature. It should however be pointed to that all the samples were in the same range with regard to the absorption capacity and that HPMC alone is not performing significantly better than the foams containing hemicellulose.

In this context, the hemicellulose-HPMC foams appeared to perform slightly better than some starch-based foams. Sjöqvist et al. reported absorption values for potato-starch foams to be in the range of about $1-4 \mathrm{~g} / \mathrm{g}$ after $1 \mathrm{~min}$ immersion and around $1 \mathrm{~g} / \mathrm{g}$ after centrifugation [10]. It should be noted that the immersion time in their experiments extended

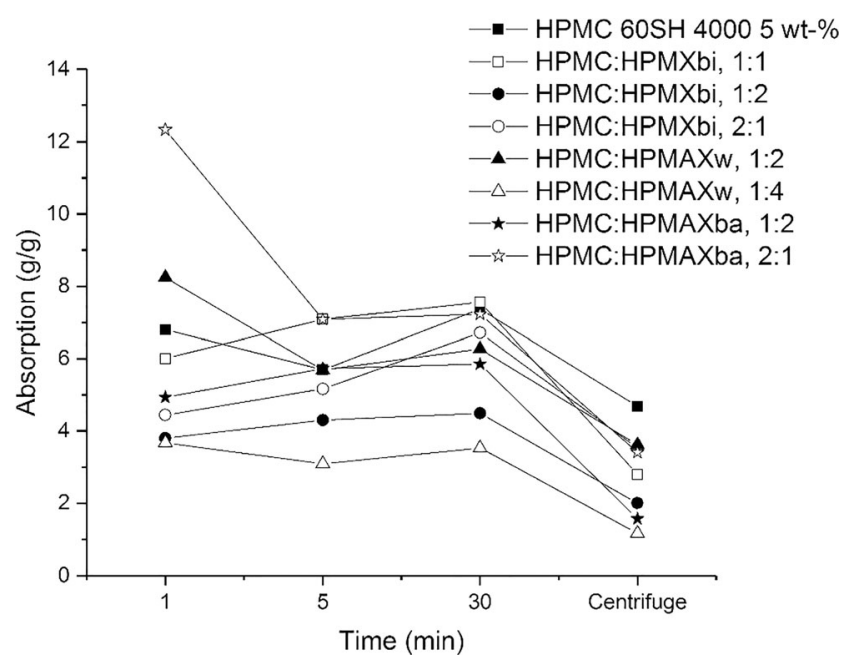

Fig. 10 The absorption capacity in $\mathrm{g} / \mathrm{g}$ after 1,5 and $30 \mathrm{~min}$ immersion in water as well as after centrifugation for $3 \mathrm{~min}$ for eight of the produced foams up to $60 \mathrm{~min}$ but the centrifugation time was only $2 \mathrm{~min}$. The absorption capacity did however not change substantially between 30 and $60 \mathrm{~min}$.

\section{Final remarks and conclusions}

It was possible to chemically modify hemicellulose from three different sources by reacting hydroxypropyl and methyl groups to the polymers. By studying the respective FTIR spectra, it was confirmed that the hemicellulose polymers had been modified as aimed for. The foamability also confirms that the modification procedure gave the thermoresponsive product.

Foams from blends of modified hemicelluloses and HPMC could be produced by a hot-mould technique. Neither of the modified hemicelluloses produced foam on their own. Some addition of HPMC thus seems necessary in order to stabilize a foam structure. This was still an improvement compared to the previous tests where HPMC and native xylan did not produce any foam. Despite the different origins of the hemicelluloses, the visual appearance of the foams was quite similar. A somewhat darker colour was however observed for the foams based on HPMAX $_{\mathrm{ba}}$ and HPMC. Actually, despite some minor differences, the shear viscosity at room temperature of the aqueous solutions, the density of the foams and the absorption capacity were all quite similar for the blends based on the modified hemicelluloses and HPMC when mixed at similar proportions.

Thus, it is potentially possible that a significant fraction of the HPMC could be substituted by a chemically modified hemicellulose when aiming at manufacturing a natural polymer-based foam. This is important in order to find value-creating applications for biopolymers, currently treated like waste materials. To further increase the interest in these types of materials from an industrial point of view, a study 
which evaluates the possibility to foam these polymers by extrusion would be valuable.

Acknowledgements The funding from the Swedish Research Council Formas is gratefully acknowledged. Further thanks are extended to the members of SmartFoam project for initiating this research.

Funding Information Open access funding provided by Chalmers University of Technology.

Open Access This article is distributed under the terms of the Creative Commons Attribution 4.0 International License (http:// creativecommons.org/licenses/by/4.0/), which permits unrestricted use, distribution, and reproduction in any medium, provided you give appropriate credit to the original author(s) and the source, provide a link to the Creative Commons license, and indicate if changes were made.

\section{References}

1. Global plastic production from 1950 to 2016 (in million metric tons) (2018) Statista, PlasticsEurope (PEMRG). https://www. statista.com/statistics/282732/global-production-of-plastics-since1950/. Accessed 19 June 2018

2. Thompson RC, Moore CJ, vom Saal FS, Swan SH (2009) Plastics, the environment and human health: current consensus and future trends. Phil. Trans. R. Soc. B 364(1526)

3. Eriksen M, Lebreton LCM, Carson HS, Thiel M, Moore CJ, Borerro JC, Galgani F, Ryan PG, Reisser J (2014) Plastic pollution in the World's oceans: more than 5 trillion plastic pieces weighing over 250,000 tons afloat at sea. PLoS One 9(12):e111913

4. Chae Y, An Y (2018) Current research trends on plastic pollution and ecological impacts on the soil ecosystem: a review. Environ Pollut 240:387-395

5. Katsanevakis S (2008) In: marine pollution: new research. Nova Science Publishers, New York

6. Shogren RL, Lawton JW, Doane WM, Tiefenbacher KF (1998) Structure and morphology of baked starch foams. Polymer 39(25):6649-6655

7. Glenn G, Orts W (2001) Properties of starch-based foam formed by compression/explosion processing. Ind Crop Prod 13(2):135-143

8. Chiellini E, Cinelli P, Ilieva V, Imam S, Lawton J (2009) Environmentally compatible foamed articles based on potato starch, corn fiber, and poly(vinyl alcohol). J Cell Plast 45(1):17-32

9. Nabar Y, Narayan R, Schindler M (2006) Twin-screw extrusion production and characterization of starch foam products for use in cushioning and insulation applications. Polym Eng Sci 46(4):438451

10. Sjöqvist M, Boldizar A, Rigdahl M (2010) Processing and water absorption behavior of foamed potato starch. J Cell Plast 46(6): 497-517
11. Hu Y, Zhang S, Han D, Ding Z, Zeng S, Xiao X (2018) Construction and evaluation of the hydroxypropyl methyl cellulose-sodium alginate composite hydrogel system for sustained drug release. J Polym Res 25(7):1-12

12. Clasen C, Kulicke W (2001) Determination of viscoelastic and rheo-optical material functions of water-soluble cellulose derivatives. Prog Polym Sci 26(9):1839-1919

13. Tunç S, Duman O (2010) Preparation and characterization of biodegradable methyl cellulose/montmorillonite nanocomposite films. Appl Clay Sci 48:414-424

14. Tunç S, Duman O, Polat TG (2016) Effects of montmorillonite on properties of methyl cellulose/carvacrolbased active antimicrobial nanocomposites. Carbohydr Polym 150:259-268

15. Karlsson K, Schuster E, Stading M, Rigdahl M (2015) Foaming behavior of water-soluble cellulose derivatives: Hydroxypropyl methylcellulose and ethyl hydroxyethyl cellulose. Cellulose 22(4): 2651-2664

16. Karlsson K, Kádár R, Stading M, Rigdahl M (2016) Processing window for extrusion foaming of hydroxypropyl methylcellulose. Cellulose 23(3):1675-1685

17. Nylander F, Svensson O, Josefsson M, Larsson A, Westman G (2018) New features of arabinoxylan ethers revealed by using multivariate analysis. Carbohydr Polym 204:255-261. https://doi.org/ 10.1016/j.carbpol.2018.09.062

18. Aspinall G, Ferrier R (1957) 840. The constitution of barley husk hemicellulose. J Chem Soc 0:4188-4194

19. Höije A, Gröndahl M, Tømmeraas K, Gatenholm P (2005) Isolation and characterization of physiochemical and material properties of arabinoxylans from barley husks. Carbohydr Polym 61:266-275

20. Börjesson M, Härdelin L, Nylander F, Karlsson K, Larsson A, Westman G (2018) Arabinoxylan and Nanocellulose from a kilogram-scale extraction of barley husk. BioResources 13:62016220

21. Bigand V, Pinel C, Da Silva Perez D, Rataboul F, Huber P, PetitConil M (2011) Cationisation of galactomannan and xylan hemicelluloses. Carbohydr Polym 85(1):138-148

22. EDANA Test Methods (2015) https://www.edana.org/discovernonwovens/standard-procedures. Accessed 27 August 2018

23. Kacuráková M, Ebringerová A, Hirsch J, Hromádková Z (1994) Infrared study of arabinoxylans. J Sci Food Agric 66:423-427

24. Gruppen H, Kormelink F, Voragen A (1993) Water-unextractable Cell Wall material from wheat flour. 3. A structural model for Arabinoxylans. J Cereal Sci 18:111-128

25. Biron M (2013) Thermoplastics and thermoplastic composites2nd edn. William Andrew, Oxford

26. Calvert K, Trumble K, Webster T, Kirkpatrick L (2010) Characterization of commercial rigid polyurethane foams used as bone analogs for implant testing. J Mater Sci Mater Med 21(5): $1453-1461$

Publisher's note Springer Nature remains neutral with regard to jurisdictional claims in published maps and institutional affiliations. 